\title{
Gamma knife radiosurgery for arteriovenous malformations located in eloquent regions of the brain
}

\author{
Vijayakumar Javalkar, Pramod Pillai, Prasad Vannemreddy, Gloria Caldito ${ }^{1}$, Federico Ampil ${ }^{2}$, Anil Nanda \\ Departments of Neurosurgery, ${ }^{1}$ Bioinformatics and Computational Biology, ${ }^{2}$ Radiation Oncology, Louisiana State University Health \\ Sciences Center, Shreveport, LA, USA
}

\section{Address for correspondence: Dr. Anil Nanda, \\ Department of Neurosurgery, Louisiana State University Health \\ Sciences Center, Shreveport 1501, Kings Highway, Shreveport, LA 71130, USA \\ E-mail: ananda@Isuhsc.edu}

PMID: 19934562

DOI: $10.4103 / 0028-3886.57818$

\begin{abstract}
Background: Stereotactic radiosurgery is an effective treatment strategy for selected group of patients with cerebral arteriovenous malformations (AVMs). Aim: The aim of this study was to evaluate the obliteration rates, complications, and patient outcomes after Gamma knife radiosurgery for cerebral arteriovenous malformations (AVMs) located in eloquent regions of the brain with an emphasis on neurological morbidity. Materials and Methods: Between 2000 and December 2005, 37 patients with AVMs in eloquent locations (sensory, motor, speech, visual cortex, basal ganglia, and brain stem) underwent stereotactic radiosurgery. We retrospectively reviewed the clinical data of these patients to asses the outcomes. Of the 37 patients, only two patients had prior embolization. Three underwent prospective staged volume radiosurgery. Two patients needed redo-radiosurgery for residual AVM. Mean target volume was $9.1 \mathrm{cc}$. Three lesions had nidus volume more than $20 \mathrm{cc}$. Average marginal dose was $18.75 \mathrm{~Gy}$. The median duration of follow-up was 23 months (range, 6-60 months). 15 patients had follow-up of more than 36 months. Results: A total of 15 patients had follow-up of more than 36 months, thus available for evaluation of angiographic obliteration rates. Complete angiographic obliteration was documented in seven patients (46.7\%). Four patients experienced hemorrhage during the latency period. One patient who had subseQuent hemorrhage on follow-up developed worsening of neurological deficit. One patient developed significant sensory symptoms which resolved after steroids. No additional clinical deterioration related to treatment was noted in rest of the patients. Conclusions: AVMs located in eloquent and in deep locations can be treated safely with stereotactic radiosurgery with acceptable obliteration rates and minimal morbidity.
\end{abstract}

Key words: Arteriovenous malformation, stereotactic radiosurgery, eloquent location

\section{Introduction}

Stereotactic radiosurgery is an effective treatment strategy for selected group of patients with cerebral arteriovenous malformations (AVMs). The acceptable goals are complete obliteration of the nidus with elimination of risk of hemorrhage and with minimal morbidity. AVMs located in eloquent regions of the brain pose a significant challenge to the neurosurgeon and to the patient as well. AVMs located in deep location such as basal ganglia, thalamus, and brain stem are estimated to have hemorrhage risk more than those located in superficial location..$^{[1,2]}$ The results of microsurgical resection of AVMs located in eloquent locations of the brain are associated with morbidity and significant functional disability ${ }^{[3-5]}$ Embolization of AVMs is rarely curative and is performed to reduce the size of nidus to facilitate surgical resection or AVM obliteration by radiosurgery. ${ }^{[6]}$ In this paper we review our experience with AVMs located in eloquent locations of the brain treated with radiosurgery with an emphasis on postradiosurgery complications. 


\section{Material and Methods}

\section{Patient characteristics}

Between 2000 and 2005, 37 patients with AVMs located in internal capsule, thalamus, brain stem, and eloquent cortex (motor, sensory, visual and speech areas) underwent stereotactic radiosurgery. There were 17 men and 20 women with age ranging from 20 to 63 years. A total of 17 patients (46\%) presented with seizures and 10 (27\%) presented with bleed [Figure 1]. Of the 37 patients, two had prior embolization. None of the patients had undergone prior surgery. A total of $18 \mathrm{AVMs}$ were located in the perirolandic area (motor area $=8$, sensory area $=2$, sensory and motor $=8$ ). Other locations are visual area $(\mathrm{n}=8)$, speech area $(\mathrm{n}=3)$, basal ganglia $(\mathrm{n}=3)$, and posterior third ventricle and mid brain $(n=3)$ [Table 1]. Majority of the AVMs were Spetzler martin grade 3 and 4 [Table 2]. No patient had AVM of grade I. Mean treatment volume was $9.6 \mathrm{cc}$ ranging from $0.5 \mathrm{cc}$ to $37.4 \mathrm{cc}$ [Figure 2]. Three lesions had nidus volume more than $20 \mathrm{cc}$.

\section{Radiosurgical technique}

Radiosurgery was performed using 201-source, cobolt-60 Gamma Knife (Elekta Instruments, Atlanta, GA). Dose planning was based on biplanar stereotactic cerebral angiography and MRI. The prescription dose was jointly decided by the neurosurgeon, radiation oncologist and the medical physicist. Average marginal dose was $18.75 \mathrm{~Gy}$. Three patients underwent prospective staged volume radiosurgery. Two patients underwent repeat radiosurgery for residual AVM. For repeat radiosurgery cases we prefer to use reduced dose (reduced by $25 \%$ of the initially used dose for the same volume). In general, for de novo AVM lesions, marginal dose selection has been based on volume of the nidus, location of the nidus and predicted dose-response relationship for a 3\% risk of brain parenchymal necrosis. The optimal dose is selected by balancing the expected obliteration rate (dose response curve)

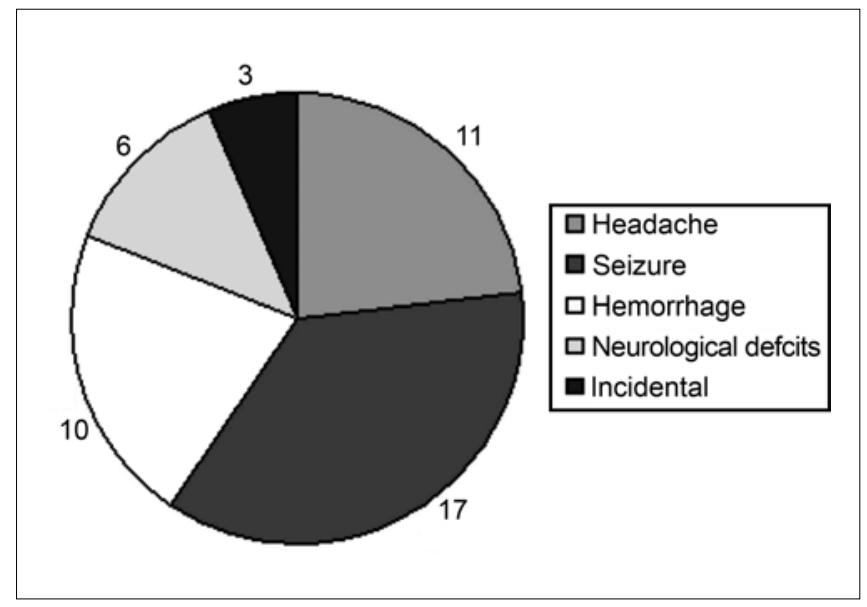

Figure 1: Summary of clinical presentations and the corresponding risk rate (dose complication curve) ${ }^{[7]}$ One needs to take into account the degree of eloquence as well. Other factors such as "tightness" of the radio surgical plan may influence the marginal dose. If the plan is very highly conformal one may prescribe a relatively higher dose. Accumulated radio surgical experience may help to choose optimal marginal dose for a given AVM.

\section{Follow-up evaluation}

Postradiosurgical clinical examinations and MRI scans were sought at six-month intervals for the first year and annually thereafter. Patients were initially investigated with MRI at the end of three years. If the MRI scans were suggestive of obliteration then the result was confirmed with angiogram. We wait for another year for angiogram if the MRI scan at the end of three years was not suggestive of complete obliteration. Repeat radiosurgery was considered if the AVM does not obliterate in total at the end of four years. The median duration of follow-up

\begin{tabular}{lc}
\hline Table 1: Location of arteriovenous malformation & \\
\hline Location & $\mathrm{n}(\%)$ \\
\hline Motor area & $8(21.6)$ \\
Sensory & $2(5.4)$ \\
Sensory-motor & $8(21.6)$ \\
Speech & $3(8.1)$ \\
Visual cortex & $8(21.6)$ \\
Basal ganglia & $3(8.1)$ \\
Hippocampus & $1(2.7)$ \\
Mid brain and posterior third ventricle & $3(8.1)$ \\
Left insular & $1(2.7)$ \\
\hline
\end{tabular}

\begin{tabular}{lc}
\hline Table 2: Spetzler Martin grade & \\
\hline Spetzler Martin grade & $\mathrm{n}(\%)$ \\
\hline 1 & $0(0.0)$ \\
2 & $9(24.3)$ \\
3 & $13(35.1)$ \\
4 & $13(35.1)$ \\
5 & $2(5.4)$ \\
\hline
\end{tabular}

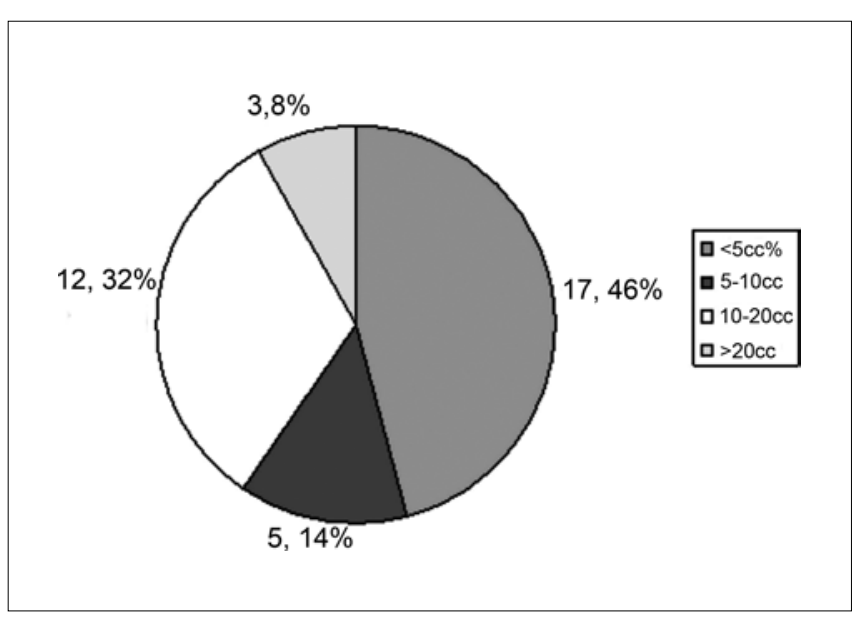

Figure 2: Volume of the nidus in cc 
was 23 months (range, 6-60 months). Only 15 patients had follow-up of more than 36 months.

\section{Statistical analysis}

Association of various covariates on complete obliteration was tested using simple logistic regression analysis. The covariates that were tested are: Sex (male, female); hemorrhage (yes, no); spetzler martin grade; age; isodose volume; central dose; and marginal dose. Statistical analysis was performed using SPSS ver. 13.0 software.

\section{Results}

Out of 37 patients, only 15 (40\%) had follow-up of more than 36 months, thus, allowing evaluation of obliteration rate. Total obliteration was observed in seven (46.5\%), near total obliteration in three and moderate obliteration in three. Repeat radiosurgery was performed in two patients. The two patients had repeat radiosurgery at 49.4 and 55 months, respectively after the initial treatment and the marginal dose that was used to treat was $20 \mathrm{~Gy}$ and $21 \mathrm{~Gy}$, respectively. Four patients $(10.8 \%)$ had hemorrhage after radiosurgery [Table 3]. The annual risk of bleeding after radiosurgery was $5 \%$ in a total of 76 patient followup years. Of these four only one had prior hemorrhage before radiosurgery. All of them recovered completely except one. Seven patients (19\%) developed peri AVM imaging changes, of which three patients required steroid administration. One patient developed significant sensory symptoms which resolved after steroids. Out of the 17 patients who presented with seizures, 12 were stable with single medication. Only five needed polypharmacy to control the seizures. Of the 11 patients who presented with headache, seven did not complain of headache on follow-up and four had worsening of headache. One patient who had subsequent hemorrhage on followup developed worsening of neurological deficit. No additional clinical deterioration related to treatment was noted in rest of the patients. Association of each covariate on complete obliteration was studied using simple logistic regression analysis [Table 4]. The tested covariates were: Sex (male, female); hemorrhage (yes, no); Spetzler martin grade; age; isodose volume; central dose; and marginal dose. None of them reached statistical significance.

\section{Discussion}

Stereotactic radiosurgery is an established treatment in the management of arteriovenous malformation of the brain. The goal is to completely obliterate the AVM with minimal side effects, thus, reducing the risk of hemorrhage. Surgery and stereotactic radiosurgery are both viable options for the management of AVM located in noneloquent and superficial location. The annual risk of hemorrhage is estimated to be approximately $2-4 \% .{ }^{[8,9]}$ AVMs located in deep locations such as basal ganglia, thalamus, and brain stem are estimated to have hemorrhage risk more than the AVM located in superficial location. ${ }^{[1,2]}$ Not only the increased risk of bleeding, hemorrhage into an eloquent area will result in devastating neurological deficit; hence, conservative management is not a good option for this subset of AVM.

In the literature, the reported obliteration rates after radiosurgery vary depending on the dose and volume of the nidus. Pollock et al., ${ }^{[10]}$ in a multivariate analysis of 220 patients reported that smaller volume, fewer draining veins, younger patient age and hemispheric AVM location are associated with successful radiosurgery. Flickinger et al., ${ }^{[7]}$ documented an obliteration rate of $73 \%$ in 264 AVMs. They generated a dose responsive curve for AVM obliteration and documented that above 25 Gy there was no improvement in obliteration rate. The optimal dose is selected by balancing the expected obliteration rate (dose response curve) and the corresponding risk rate (dose complication curve). ${ }^{[7]}$ In practice, maximum dose can be prescribed for small AVM and AVM located in noneloquent areas of the brain. In case of treatment of AVM located in eloquent areas dose selection is very important in order to reduce the side-effects but this might result in decreased chance of obliteration.

The complete obliteration rates in AVM located in eloquent areas is not as high as those located in non eloquent areas. Zabel et al., ${ }^{[11]}$ reported a complete obliteration rate of $50 \%$ and $65 \%$ after 3 and 5 years respectively in AVMs located in deep and eloquent areas. Pollock et al., ${ }^{[12]}$ reported $71 \%$ complete angiographic obliteration (single stage and second stage)

\begin{tabular}{|c|c|c|c|c|c|c|}
\hline \multicolumn{7}{|c|}{ Table 3: Hemorrhage during latency period } \\
\hline Location & Previous bleed & $\begin{array}{c}\text { Rebleed in } \\
\text { latency }\end{array}$ & $\begin{array}{l}\text { Presentation at } \\
\text { rebleed }\end{array}$ & Hematoma & $\begin{array}{l}\text { Management } \\
\text { of hematoma }\end{array}$ & $\begin{array}{l}\text { Outcome of } \\
\text { rebleed }\end{array}$ \\
\hline Thalamus & No & $28 \mathrm{mo}$ & Headache & $\begin{array}{l}\text { Small, no mass } \\
\text { effect }\end{array}$ & Conservative & $\begin{array}{l}\text { Recovered without } \\
\text { deficits }\end{array}$ \\
\hline Motor strip & Yes & $24 \mathrm{mo}$ & $\begin{array}{l}\text { Weakness of arm } \\
\text { and leg }\end{array}$ & $\begin{array}{l}3 \times 3 \mathrm{~cm} \\
\text { hematoma, mild } \\
\text { shift }\end{array}$ & Conservative & $\begin{array}{l}\text { Partial recovery in } \\
\text { motor function }\end{array}$ \\
\hline Perirolandic & No & $60 \mathrm{mo}$ & Headache & Small & Conservative & $\begin{array}{l}\text { Recovered without } \\
\text { deficits }\end{array}$ \\
\hline Thalamic & No & $6 \mathrm{mo}$ & Numbness & Small & Conservative & $\begin{array}{l}\text { Recovered without } \\
\text { deficits }\end{array}$ \\
\hline
\end{tabular}




\begin{tabular}{lcc}
\hline $\begin{array}{l}\text { Table 4: Association of each covariate on complete } \\
\text { obliteration using simple logistic regression analysis }\end{array}$ \\
\hline Variable & $\begin{array}{c}\text { Odds ratio, } \\
95 \% \mathrm{Cl} \text { for OR }\end{array}$ & $P$ value \\
\hline Sex: F vs.M & $1.17(0.22,6.14)$ & 0.86 \\
Hemorrhage: No vs.yes & $1.07(0.17,6.59)$ & 0.94 \\
Spetzler martin grade & $1.05(0.43,2.56)$ & 0.91 \\
Age & $1.01(0.95,1.08)$ & 0.71 \\
Size & $1.00(0.94,1.06)$ & 0.93 \\
Isodose volume & $0.97(0.87,1.08)$ & 0.55 \\
Central dose & $1.08(0.83,1.39)$ & 0.57 \\
Marginal dose & $1.10(0.67,1.81)$ & 0.7 \\
\hline OR - Odds ratio &
\end{tabular}

in 34 postgeniculate visual pathway AVM. Hadjipanayis et al., ${ }^{[13]}$ reported an overall $70 \%$ obliteration rate for motor cortex AVM. They documented that in volumes less than $3 \mathrm{ml}$, the obliteration rate was $87 \%$. Only one patient experienced worsening of neurological function after radiosurgery. Pollock et al., ${ }^{[14]}$ documented an excellent outcome (obliteration of the lesion without any deficit) in $39 \%$ of patients after one radiosurgical procedure and in $48 \%$ after one or more procedure in a series of 58 AVM located in basal ganglia, thalamus, and brainstem. Maruyama et al., ${ }^{[15]}$ reported an obliteration rate of $66 \%$ in a series of 50 brain stem AVMs. The rate of persistent neurological complications in patients treated using magnetic resonance based dose planning was 7\% and the neurological complication rate in patients treated before 1993 was $20 \%$. In the present series the obliteration rate was $46.5 \%$. The obliteration rates reported are less than that published in literature. Out of the 37 patients only 15 patients had follow-up more than 36 months, thus allowing complete obliteration rates.

In our series, two patients underwent repeat radiosurgery. The two patients had repeat radiosurgery at 49.4 months and 55 months after the initial treatment. The marginal dose that was used to treat was 20 Gy and $21 \mathrm{~Gy}$, respectively. It's difficult to predict what factors were responsible for failure of the treatment in our cases. The factors that are attributed for treatment failure in the literature are incomplete angiographic definition of the nidus, recanalization of the AVM nidus after prior embolization, incomplete nidus recognition caused by compression of the AVM vessels in the presence of hematoma. ${ }^{[16]}$ The important question is whether to reduce the dose at repeat radiosurgery or not. In one study, the dose response curve for repeated radiosurgery was similar to that for initial radiosurgery. ${ }^{[17]}$ In that study, ${ }^{[17]}$ the authors feel that dose prescription should not be reduced for repeated treatment. Adverse radiation effects ( $5 \%$ symptomatic) may be some what higher than those found in cases not previously subjected to radiation, but appears to be acceptable. For repeat radiosurgery cases we prefer to use reduced dose (reduced by $25 \%$ of the initially used dose for the same volume).
Four patients had intracranial hemorrhage following radiosurgery. Interestingly out of four patients only one had history of hemorrhage before radiosurgery. The number of patients $(10.8 \%)$ with hemorrhage during latency period is comparatively higher in our study. In the literature percentage of patients with rebleeding after radiosurgery varied between 3.4 to $10 \% .{ }^{[18,19]}$ In another paper where authors have studied the outcome in centrally located AVM, ${ }^{[20]} 9.4 \%$ of the patients had a rebleed following GKS. In another study involving the AVM located in basal ganglia, internal capsule and thalamus, authors reported a hemorrhage rate of $9.5 \%$ in the first year, $4.7 \%$ in the second year, and $0 \%$ thereafter. ${ }^{[21]}$ In the study by Karlsson et al., ${ }^{[22]}$ $23 \%$ of the patients had experienced hemorrhage in the latency period with an annual risk of bleeding of $7 \%$. Risk factors that may predispose a patient to rebleeding are angiographic factors such as venous ectasia/ stenosis/hypertension, presence of intranidal aneurysm, periventricular location, lower marginal dose, large volume of the nidus, dose given to the nidus, and prior hemorrhage. ${ }^{[19]}$

Microsurgical excision for AVM located in critical location is associated with significant morbidity. $\mathrm{O}^{\prime}$ Laoire et al. ${ }^{[5]}$ reported $11 \%$ severe disability and $5 \%$ mortality. Kunc ${ }^{[4]}$ reported $61 \%$ reduced capacity to work and $11 \%$ disability rate. Heros et al., ${ }^{[23]}$ reported $7.8 \%$ morbidity and $0.6 \%$ mortality rates. Schaller and Schramm ${ }^{[24]}$ reported a $6.1 \%$ rate of permanent significant neurological deficits after microsurgical removal of small AVMs in eloquent regions.

For central AVMs (brain stem, basal ganglia, thalamus), the incidence of radiation induced permanent deficits varied between $0-14 \%$ following stereotactic radiosurgery. ${ }^{[20]}$ For rolandic AVM treated with radiosurgery, in one study two patients $(5.3 \%)$ had adverse effects lasting more than six months. ${ }^{[21]}$ In another study only one patient $(3 \%)$ had radiosurgery induced neurological worsening following treatment for motor cortex AVM. ${ }^{[13]}$ In the series by Pollack et al., no patient developed a new permanent homonymous hemianopsia following stereotactic radiosurgery for postgeniculate visual pathway AVMs. ${ }^{[12]}$ In our study, only one patient who had subsequent hemorrhage on follow-up developed worsening of neurological deficit. No additional clinical deterioration related to treatment was noted in rest of the patients. There was no incidence of radiation necrosis, cyst formation, or radiation induced malignancy in our patients.

\section{Conclusions}

Stereotactic radiosurgery can be performed with acceptable obliterations rates and with minimal morbidity in patients 
with AVMs in deep locations and in eloquent areas of the brain. This experience emphasizes the difficulty in treating patients with AVM located in critical locations of the brain, the majority of who are also poor candidates for microsurgical resection or embolization.

\section{References}

1. Sasaki T, Kurita H, Saito I, Kawamoto S, Nemoto S, Terahara A, et al. Arteriovenous malformations in the basal ganglia and thalamus: Management and results in 101 eases. J Neurosurg 1998;88:285-92.

2. Lawton MT, Hamilton MG, Spetzler RF. Multimodality treatment of deep arteriovenous malformations: Thalamus, basal ganglia and brain stem. Neurosurgery 1995;37:29-36.

3. Da Pian R, Pasqualin A, Scienza R, Vivenza C. Microsurgical treatment of ten arteriovenous malformations in critical areas of cerebrum. J Microsurg 1980;1:305-20.

4. Kunc Z. Surgery of arteriovenous malformation in the speech and motor-sensory regions. J Neurosurg 1974;40:293-303.

5. O'Laoire SA. Microsurgical treatment of arteriovenous malformations in critical areas of the brain. Br J Neurosurg 1995;9:347-60.

6. Paulsen RD, Steinberg GK, Norbash AM, Marcellus ML, Marks MP. Embolization of basal ganglia and thalamic arteriovenous malformations. Neurosurgery 1999;44:996-7.

7. Flickinger JC, Pollock BE, Kondziolka D, Lunsford LD. A doserespone analysis of arteriovenous malformation obliteration after Radiosurgery. Int J Radiat Oncol Biol Phys 1996;36:873-9.

8. Brown RD Jr, Wiebers DO, Forbes G, O'Fallon WM, Piepgras DG, Marsh WR, et al. The natural history of unruptured intracranial arteriovenous malformations. J Neurosurg 1988;68:352-7.

9. Crawford PM, West CR, Chadwick DW, Shaw MD. Arteriovenous malformation of the brain: Natural history in un operated patients. J Neurol Neurosurg Psychiatry 1986;49:1-10.

10. Pollock BE, Flickinger JC, Lunsford LD, Maitz A, Kondziolka D. Factors associated with successful arteriovenous malformation radiosurgery. Neurosurgery 1998;42:1239-47.

11. Zabel-du Bois A, Milker-Zabel S, Huber P, Schlegel W, Debus J. Stereotactic Linac-based radiosurgery in the treatment of cerebral aretriovenous malformations located deep, involving corpus callosum, motor cortex, or brain stem. Int J Radiat Oncol Biol Phys 2006;64:1044-8.

12. Pollock BE, Lunsford LD, Kondziolka D, Bissonette DJ, Flickinger JC. Stereotactic radiosurgery for postgeniculate visual pathway arteriovenous malformations. J Neurosurg 1996;84:437-41.

13. Hadjipanayis CG, Levy EI, Niranjan A, Firlik AD, Kondziolka D, Flickinger JC, et al. Stereotactic Radiosurgery for Motor Cortex region arteriovenous malformations. Neurosurgery 2001;48:70-7.

14. Pollock BE, Gorman DA, Brown PD. Radiosurgery for arteriovenous malformations of the basal ganglia, thalamus and brainstem. J Neurosurg 2004;100:210-4.

15. Maruyama K, Kondziolka D, Niranjan A, Flickinger JC, Lunsford LD. Stereotactic radiosurgery for brain stem arteriovenous malformations: Factors affecting outcome. J Neurosurg 2004;100:407-13.

16. Pollock BE, Kondziolka D, Lunsford LD, Bissonette D, Flickinger JC. Repeat stereotactic radiosurgery of arteriovenous malformations: Factors associated with incomplete obliteration. Neurosurgery 1996;38:318-24.

17. Maesawa S, Flickinger JC, Kondziolka D, Lunsford LD. Repeated radiosurgery for incompletely obliterated arteriovenous malformations. J Neurosurg 2000;92:961-70.

18. Liscák R, Vladyka V, Simonová G, Urgosík D, Novotný J Jr, Janousková L, et al. Arteriovenous malformations after Leksell gamma knife radiosurgery: Rate of obliteration and complications. Neurosurgery 2007;60:1005-14.

19. Kasliwal MK, Kale SS, Gupta A, Kiran NA, Sharma MS, Sharma BS, et al. Outcome after hemorrhage following Gamma Knife surgery for cerebral arteriovenous malformations. J Neurosurg 2009; 110:1003-9.

20. Kiran NA, Kale SS, Kasliwal MK, Vaishya S, Gupta A, Singh Sharma M, et al. Gamma knife radiosurgery for arteriovenous malformations of basal ganglia, thalamus and brainstem-a retrospective study comparing the results with that for AVMs at other intracranial locations. Acta Neurochir (Wien) 2009 May 5. [Epub ahead of print].

21. Andrade-Souza YM, Zadeh G, Scora D, Tsao MN, Schwartz ML. Radiosurgery for basal ganglia, internal capsule, and thalamus arteriovenous malformation: Clinical outcome. Neurosurgery 2005;56:56-63.

22. Karlsson B, Jokura H, Yamamoto M, Söderman M, Lax I. Is repeated radiosurgery an alternative to staged radiosurgery for very large brain arteriovenous malformations? J Neurosurg 2007;107:740-4.

23. Heros RC, Korosue K, Diebold PM. Surgical excision of cerebral arteriovenous malformations: Late results. Neurosurgery 1990;26:570-8.

24. Schaller C, Schramm J. Microsurgical results for small arteriovenous malformations accessible for radiosurgical or embolization treatment. Neurosurgery 1997;40:664-74.

Accepted on 06-08-2009

Source of Support: Nil, Conflict of Interest: None declared. 